\title{
Oral health status in children with haemophilia - a comparative study
}

N S Venkatesh Babu, Milind Shah, Purna Patel

People with haemophilia may neglect their oral hygiene due to the fear of bleeding during brushing, leading to an increase in dental caries, gingivitis and periodontitis in this group. The available literature shows very few studies on the oral health status of children with haemophilia. The aim of the current study, therefore, was to assess the oral health status of children with haemophilia in comparison with healthy children. Data were collected from a study and control groups of haemophilic and healthy children aged 6-16 years. All children were examined under standardised conditions by a single qualified examiner and Plaque Index (PI), Modified Gingival Index (MGI) and permanent decayed, missing, and filled teeth (DMFT) and primary $\mathrm{dmft}$ index were recorded. A questionnaire distributed to the parents was analysed using Chi-Square and Kruskal-Wallis test, and showed a significant difference in GMI and DMFT and dmft scores between the study and control groups, a lower level of parental education level in the study group, a difference in the frequency of tooth brushing between the two groups, and a statistically higher frequency of sugar consumption among the children with haemophilia. The study concluded that children with haemophilia have poor oral health status compared to healthy children. Parental education levels, beliefs and attitude towards dental health have an impact on the child's overall dental health. This indicates a need for early intervention by dental services as a preventive measure for children with haemophilia.

Keywords: haemophilia, DMFT, dmft index, Plaque Index, children

Dental caries are the single most prevalent chronic disease of childhood [1,2]. They are not distributed evenly within the general population, with certain subgroups known to be affected at substantially higher rates than others [1]. Children with special health care needs are among those at increased risk for poor dental health $[1,2,3]$. According to the UN Development Programme (UNDP), around 80\%

N S Venkatesh Babu, Professor and Head, Department of Pediatric and Preventive Dentistry, V.S. Dental College and Hospital, K.R.Road, V.V.Puram, Bengaluru 5600004, Karnataka, India. E-mail: drnsvbabu@gmail.com

Milind Shah, postgraduate student, Department of Pediatric and Preventive Dentistry, V.S. Dental College and Hospital, K.R.Road, V.V.Puram, Bengaluru 5600004, Karnataka, India

Purna Patel, postgraduate student, Department of Pediatric and Preventive Dentistry, V.S. Dental College and Hospital, K.R.Road, V.V.Puram, Bengaluru 5600004, Karnataka, India

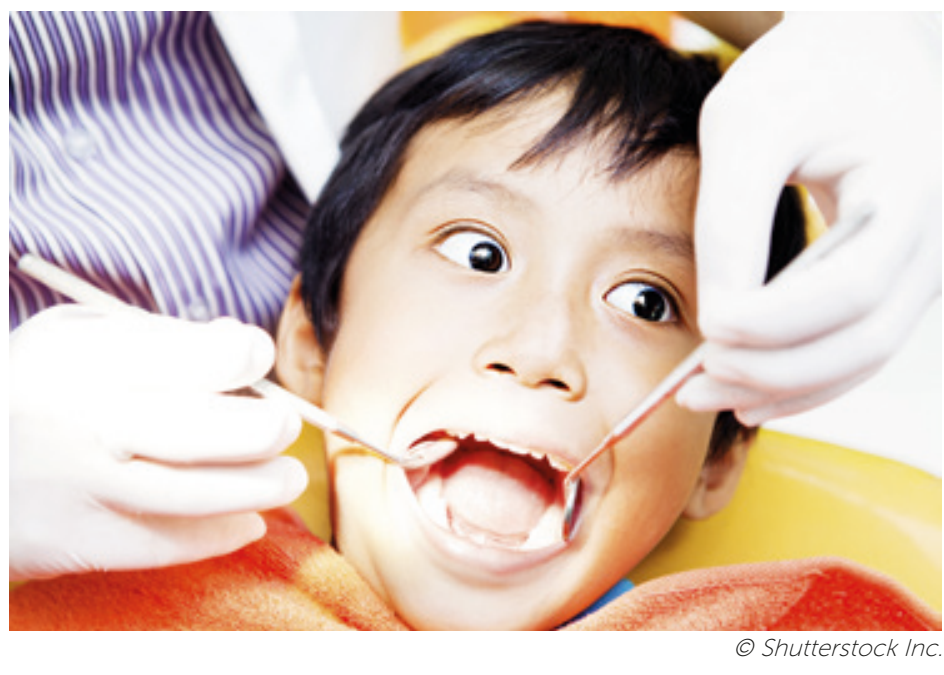

of people with disabilities live in developing countries [4]. The National Sample Survey Organization (NSSO) holds that there are 18.49 million persons with disabilities in India, which constitutes around $1.8 \%$ of the total population [5].

Dental care is one of the greatest unmet health care needs among children with special health care needs in India. Delayed access to dental care can lead to serious consequences for all children, but can be particularly serious for children with chronic medical conditions and CSHCN. Haemophilic children are amongst those who require special health care needs. Incidence of haemophilia in Indian population is 1 in 10,000 live births [6]

Patients with haemophilia generally do not pay sufficient attention to their dental care. Despite advances in knowledge of haemostasis and treatment of bleeding disorders, neglect of oral hygiene remains an issue among haemophiliacs due to a fear of bleeding during brushing [7]. It has been found that healthy children have more regular brushing habits than children with haemophilia. Hence, poor oral hygiene in haemophilic children causes an increase in incidences of dental caries, gingivitis and periodontitis in this group [7].

Oral health instruction is the responsibility of all the members of the dental health care team. Receiving appropriate instruction develops an awareness in the patient of the need to return regularly for professional prophylaxis, examination and treatment. Appropriate dental care is necessary for all individuals; however, the issue gains more importance as dental care affects the general health of haemophilic patients [8]. Confronted with the specific complexities of the disease, the families of haemophilic patients do not pay sufficient attention to their dental care 
Table 1: Comparison of mean scores between different indices

\begin{tabular}{|l|l|l|l|}
\hline Index & Study Group Median (IQR) & Control Group Median (IQR) & \multicolumn{1}{l|}{ P-value } \\
\hline DMFT & $4.0(2.0,5.0)$ & $1.0(1.0,2.0)$ & $<0.001^{\star}$ \\
\hline dmft index & $3.0(2.0,3.0)$ & $2.0(1.0,3.0)$ & $0.011^{\star}$ \\
\hline PI & $1.0(1.0,1.0)$ & $1.0(1.0,1.0)$ & 0.071 \\
\hline MGI & $2.0(1.0,2.0)$ & $0.0(0.0,1.0)$ & $<0.001^{\star}$ \\
\hline
\end{tabular}

[9].

There has been little research on the oral health of individuals with haemophilia in India, and the available literature tends to focus more on oral surgical and periodontal management in haemophilia. The aim of this study was to assess the oral health status of haemophilic children in Bangalore city, to compare this with healthy children, and to evaluate the relationship of children's dental health with the educational status of their parents.

\section{Materials and Methods}

The present comparative study to assess oral health status in children with haemophilia collected data from a study group of 100 children, aged between 6-16 years, registered under the Haemophilia Society of Bangalore. Control group data was collected from 100 healthy children who visited the Department of Paediatric and Preventive Dentistry at the V.S. Dental College and Hospital, Bangalore, for a routine dental check-up. The children in the two groups were matched based on age and gender. Institutional ethical committee clearance was obtained. Signed, written, informed consent was obtained from the parents/guardians of all children participating in the study.

All children in the study and control groups were examined under standardised conditions by a single qualified examiner; Plaque Index (PI), Modified Gingival Index (MGI) [10] and permanent decayed, missing, and filled teeth (DMFT) and primary dmft index were recorded. A questionnaire was distributed to all parents, including details regarding the children's oral and dietary habits, and the parents' level of education and oral habits $[11,12]$.

All children and parents were educated and motivated with regard to the severity and prognosis of the dental aspects of haemophilia, and maintenance of good oral hygiene. The children were given comprehensive dental treatment with emphasis on preventive measures, and advised to attend a regular dental check-up once every three months.

Once the observations were compiled, statistical analyses of the results were undertaken using Kruskal-Wallis and Chi-Square tests. Comparison between various indices in the study and control groups was made using the MannWhitney $U$ test; the level of significance was determined to be $\mathrm{P}<0.05$.

\section{Results}

There were $98(98 \%)$ cases of haemophilia A and $2(2 \%)$ cases of haemophilia B in the study. Of the 100 children with haemophilia, $48(48 \%), 20(20 \%)$ and 32 (32\%) had severe, moderate and mild haemophilia respectively.
The DMFT and dmft index scores of children with haemophilia were found to be statistically higher than the control group. The MGl scores of the children with haemophilia were also statistically higher than control group $(\mathrm{P}<0.001)$. No difference was found in $\mathrm{Pl}$ between the study and control group (Table 1).

The DMFT, dmft index, MGl and $\mathrm{Pl}$ scores revealed statistically significant differences $(P<0.05)$ between the groups with severe, moderate and mild haemophilia. Comparison of indices between severe and moderate haemophilia revealed a statistically significant difference between DMFT, dmft, MGI and PI. Comparison of indices between severe and mild haemophilia revealed a statistically significant difference between DMFT and $\mathrm{dmft}$ index. There was no significant difference in DMFT, dmft, MGl and PI scores between moderate and mild haemophilia (Tables 2-5)

Data obtained from the questionnaire distributed to parents of children in the study and control groups revealed that $26 \%$ children had a history of sugar exposure more than three times a day in the study group, whereas in the control group only $5 \%$ gave a similar history. The difference regarding sugar exposure between the two groups was found to be statistically significant with a $P$ value $<0.001$. A statistically significant difference was also found in the prevalence of tooth brushing between the study and control groups. In the study group, the number of children who never brushed their teeth was significantly higher than in the control group $(P=0.002)$ (Table 6).

Parental education levels were statistically lower in the study group than in the control group, with a $P$ value of $<0.05$. Parents of $17 \%$ children in the study group brushed their teeth twice a day, compared to $28 \%$ in the control group. This difference was statistically significant with $P$ value of 0.043 . A statistically higher number of children in the control group had visited a dentist in the past $(P<0.001)$ and received dental treatment $(P=0.007)$ in comparison to the study group (Table 6).

\section{Discussion}

Children with haemophilia constitute a very small proportion of the population and there are few studies concerning dental aspects of the disease. However, the literature agrees that haemophiliacs are a priority group for dental care.

In the present study, the DMFT and dmft index values were significantly higher in the study group as compared to the control group. The higher prevalence of dental caries in the study group could be attributed to high frequency of sugar consumption and improper oral hygiene habits. Higher 
Table 2: Comparison of DMFT index according to haemophilia type

\begin{tabular}{|c|c|c|c|c|c|}
\hline Group & Median (IQR) & P- value & Severe to Moderate & Severe to Mild & Moderate to Mild \\
\hline Severe & $3.0(2.0,4.0)$ & \multirow{3}{*}{$0.015^{*}$} & \multirow{3}{*}{$0.015^{*}$} & \multirow{3}{*}{$0.047^{*}$} & \multirow{3}{*}{0.41} \\
\hline Moderate & $4.0(3.0,5.0)$ & & & & \\
\hline Mild & $4.0(3.0,5.0)$ & & & & \\
\hline
\end{tabular}

* Indicates statistically significant at 5\% level of significance; IQR: Interquartile range

Table 3: Comparison of dmft index according to haemophilia type

\begin{tabular}{|c|c|c|c|c|c|}
\hline Group & Median (IQR) & P-value & Severe to Moderate & Severe to Mild & Moderate to Mild \\
\hline Severe & $5.0(4.0,5.0)$ & \multirow{3}{*}{$<0.001^{*}$} & \multirow{3}{*}{$<0.001^{*}$} & \multirow{3}{*}{$<0.001^{*}$} & \multirow{3}{*}{0.725} \\
\hline Moderate & $2.0(1.0,2.0)$ & & & & \\
\hline Mild & $2.0(1.0,2.0)$ & & & & \\
\hline
\end{tabular}

* Indicates statistically significant at $5 \%$ level of significance

Table 4: Comparison of Plaque Index (PI) according to haemophilia type

\begin{tabular}{|c|c|c|c|c|c|}
\hline Group & Median (IQR) & P-value & Severe to Moderate & Severe to Mild & Moderate to Mild \\
\hline Severe & $2.0(1.0,2.0)$ & \multirow{3}{*}{$0.03^{*}$} & \multirow[t]{3}{*}{$0.03^{*}$} & \multirow[t]{3}{*}{0.079} & \multirow[t]{3}{*}{0.404} \\
\hline Moderate & $1.0(1.0,2.0)$ & & & & \\
\hline Mild & $1.0(1.0,2.0)$ & & & & \\
\hline
\end{tabular}

* Indicates statistically significant at 5\% level of significance

Table 5: Comparison of Modified Gingival Index (MGI) according to haemophilia type

\begin{tabular}{|c|c|c|c|c|c|}
\hline Group & Median (IQR) & P- value & Severe to Moderate & Severe to Mild & Moderate to Mild \\
\hline Severe & $1.0(0.0,1.0)$ & \multirow{3}{*}{$0.03 *$} & \multirow{3}{*}{$0.038^{*}$} & \multirow{3}{*}{0.146} & \multirow{3}{*}{0.285} \\
\hline Moderate & $1.0(1.0,2.0)$ & & & & \\
\hline Mild & $1.0(1.0,1.0)$ & & & & \\
\hline
\end{tabular}

* Indicates statistically significant at 5\% level of significance

caries index in the haemophilia children were also reported in studies by Azhar et al [13], Kabil et al [14] and Alpkiliç et al [7]. No significant difference between control and study groups was found by Mielnik-Błaszczak [15] and Ziebolz et al [16]. However, Boyd and Kinirons [17] and Sonbol et al [18] reported study groups as having less caries than control groups. In a study involving haemophilic children in Northern Ireland, Boyd and Kinirons reported the reasons for this group having less incidence of caries than the general population as being due to patients and parents being better motivated as to the prognosis and effects of haemophilia on oral tissues, and improved oral hygiene habits and dental treatment [17].

Children with haemophilia are at high risk of developing poor gingival health. This is a consequence of neglected or insufficient tooth brushing due to the fear of bleeding while brushing, in addition to the factors that cause increased dental caries, which may include confounding factors such as lifestyle differences, oral hygiene practices; and biological determinants (i.e. a difference in underlying susceptibility). In the present study, the gingival index scores were significantly higher in the study group as compared to the control group. Similar findings were obtained in the study by Alpkiliç et al [7].

In the present study, $18 \%$ of haemophilic children did not brush their teeth due to the fear of bleeding while brushing. Perhaps most striking is the finding reported in the study by
Kabil et al, who found that $48.3 \%$ of Egyptian children with haemophilia did not carry out any oral hygiene practices [14]. In the current study, only $6 \%$ of haemophilic children brushed their teeth two or more times a day, compared to $19 \%$ in healthy children. Similar results were obtained by Alpkiliç et al, who found that children in the control group were more likely to be regular brushers [7].

As children usually look to their parents as role models in oral hygiene habits, given the lack of oral care shown by the parents of haemophilic children in the present study, it is difficult to expect favourable behaviour from the children with regards to their brushing habits. Parental education levels were statistically lower in the study group than in the control group, one reason for this being due to poor socioeconomic background. This finding indicates a lack of awareness and adequate knowledge amongst the parents regarding oral hygiene and the means of preventing dental disease, which in turn has resulted in gross neglect of the oral health of children with haemophilia.

People with haemophilia have high caries prevalence and treatment needs compared to the general population. Regular dental care is therefore of prime importance for this group of children. However, in the present study, only $48 \%$ of children in the study group had visited a dentist, of which less than one quarter $(23 \%)$ had received any kind of dental treatment. Regular attendance at a dentist has been shown to confer oral health benefits [19]. However, 
Table 6: Questionnaire

\begin{tabular}{|c|c|c|c|c|}
\hline & Question & Study group $(n=100) \%$ & Control group $(n=100) \%$ & P-value \\
\hline 1. & Did you breastfeed your child? & 83 & 79 & 0.471 \\
\hline 2. & $\begin{array}{l}\text { Did the child feed at night with } \\
\text { bottle used as pacifier? }\end{array}$ & 25 & 16 & 0.115 \\
\hline 3. & $\begin{array}{l}\text { Sugar exposure in between } \\
\text { meals } \\
\text { Once } \\
\text { Twice } \\
\text { Thrice } \\
\text { >Thrice }\end{array}$ & $\begin{array}{l}40 \\
19 \\
15 \\
26\end{array}$ & $\begin{array}{l}76 \\
18 \\
1 \\
5\end{array}$ & $<0.001^{*}$ \\
\hline 4. & $\begin{array}{l}\text { Does the child brush his/her } \\
\text { teeth? }\end{array}$ & 82 & 96 & $0.002^{*}$ \\
\hline 5. & $\begin{array}{l}\text { How often does the child brush } \\
\text { his/her teeth? } \\
\text { Once daily } \\
\text { Twice daily }\end{array}$ & $\begin{array}{l}94 \\
6\end{array}$ & $\begin{array}{l}81 \\
19\end{array}$ & $<0.001^{*}$ \\
\hline 6. & $\begin{array}{l}\text { Parental educational level } \\
\text { Primary school } \\
\text { High school } \\
\text { University graduate }\end{array}$ & $\begin{array}{l}66 \\
26 \\
8\end{array}$ & $\begin{array}{l}29 \\
43 \\
28\end{array}$ & $<0.001 *$ \\
\hline 7. & $\begin{array}{l}\text { How often do parents brush } \\
\text { their teeth? } \\
\text { Once } \\
\text { Twice }\end{array}$ & $\begin{array}{l}83 \\
17\end{array}$ & $\begin{array}{l}72 \\
18\end{array}$ & $0.043^{*}$ \\
\hline 8. & Prior dental visit & 48 & 72 & $0.001^{*}$ \\
\hline 9. & Prior dental treatment & 23 & 48 & $0.007^{*}$ \\
\hline
\end{tabular}

there is no systematic dental program for patients with haemophilia in India as has been described in the UK (e.g. Boyd and Kinirons, Sonbol et al) [17,18]. To complicate this issue, even where a program of care is available, general dentists have been shown to be reluctant to treat patients with haemophilia [20,21].

Factors influencing the oral health care of children with haemophilia are complicated. Taking into account the evidence from other studies, alongside the barriers to oral health care potentially faced by patients with haemophilia and the lack of a national strategy concerning their oral health, it is reasonable to conclude that the oral health of those with haemophilia in India is worse than that of the general population.

\section{Conclusion}

Within the limits of the present study, it can be concluded that children with haemophilia have a poor oral health status as compared to healthy children. Parental education levels, beliefs and attitude towards dental health have an impact on the child's overall dental health. Parents and children should be advised about the importance and necessity of oral care. Emphasis should be placed on the importance of preventive care and frequent dental visits to avoid the need for aggressive treatment involving greater risks. There is a need to develop immediate and effective promotional and interventional strategies for oral health in India to combat the disease in children with haemophilia.

\section{Disclosures}

The authors have advised no interests that might be perceived as posing a conflict or bias.

This is an Open Access article distributed under the terms of the Creative Commons Attribution License (http:// creativecommons.org/licenses/by/2.0), which permits unrestricted use, distribution, and reproduction in any medium, provided the original work is properly cited.

\section{References}

1. Mouradian WE, Wehr E, Crall JJ. Disparities in children's oral health and access to dental care. JAMA 2000; 284(20):2625-31.

2. US Department of Health and Human Services. Oral Health in America: A Report of the Surgeon General-Executive Summary. Rockville, Md.: US Department of Health and Human Services, National Institute of Dental and Craniofacial Research, National Institutes of Health; 2000. Available from: http://www.nidcr.nih.gov/DataStatistics/SurgeonGeneral/Report/ ExecutiveSummary.htm (accessed 22 April 2016).

3. Foster $\mathrm{H}$, Fitzgerald J. Dental disease in children with chronic illness. Arch Dis Child 2005; 90(7):703-8.

4. United Nations, International Convention on the Rights of Persons with Disabilities. Some Facts about Persons with Disabilities. New York: United Nations. 2006. Available from: http://www.un.org/disabilities/convention/ pdfs/factsheet.pdf (accessed 22 April 2016).

5. National Sample Survey Organisation (India). Disabled Persons in 
India. NSS 58th Round (July-December 2002). Report No. 485 (58/26/1). New Delhi: National Sample Survey Organisation, Ministry of Statistics and Programme Implementation, 2003. Available from: www.ilo.org/ surveydata/index.php/catalog/196/download/2058 (accessed 22 April 2016).

6. Stonebraker PHB, Bolton-Maggs J, Michael Soucie I, et al. A study of variations in the reported haemophilia prevalence around the world. Haemophilia 2010;16(1):20-32.

7. Alpkiliç BE, Albayrak H, Ak G, et al. Dental and periodontal health in children with haemophilia. J Coagul Disord 2009:15:193-9.

8. Webster WP, Courtney RM. Diagnosis and treatment of periodontal disease in the hemophiliac. In: Proceedings of the Dental Hemophilia Institute. New York: National Hemophilia Foundation, 1968.

9. Abrisham M, Tabrizizadeh M, Ghateh A. Knowledge of oral hygiene among hemophilic patients referred to Iranian Hemophilia Society. J Dent Res Dent Clin Dent Prospects 2009;3(2):60-3.

10. Lobene RR, Weatherford T, Ross NM, et al. A modified gingival index for use in clinical trials. Clin Prev Dent 1986;8(1):3-6

11. Silness J, Loe H. Periodontal disease in pregnancy. II. Correlation between oral hygiene and periodontal condition. Acta Odont Scand 1964;22:121-35

12. World Health Organization. Oral Health Surveys: Basic Methods. 3rd ed Geneva: World Health Organization, 1987.

13. Azhar S, Yazdanie N, Muhammad N. Periodontal status and IOTN interventions among young hemophiliacs. Haemophilia 2006;12(4):401-4. 14. Kabil N, ElAlfy MS, Metwalli N. Evaluation of the oral health situation of a group of Egyptian haemophilic children and their re-evaluation following an oral hygiene and diet education programme. Haemophilia 2007;13(3):287-92

15. Mielnik-Błaszczak M. Evaluation of dentition status and oral hygiene in Polish children and adolescents with congenital haemorrhagic diatheses. Int J Paediatr Dent 1999;9(2):99-103.

16. Ziebolz D, Stühmer C, Hornecker E, et al. Oral health in adult patients with congenital coagulation disorders-a case control study. Haemophilia 2011;17(3):527-31.

17. Boyd D, Kinirons M. Dental caries experience of children with haemophilia in Northern Ireland. Int J Paediatr Dent 1997:7(3):149-53.

18. Sonbol H, Pelargidou M, Lucas VS, et al. Dental health indices and caries-related microflora in children with severe haemophilia. Haemophilia 2001;7(5):468-74

19. Thomson WM, Williams SM, Broadbent JM, et al. Long-term dental visiting patterns and adult oral health. J Dent Res 2010;89(3):307-11. 20. Fiske J, Pitt Ford HE, Savidge GF, Smith MP. The expressed dental needs of patients attending a haemophilia reference centre. J Disabil Oral Health 2000;1:20-5

21. Parry JA, Khan FA. Provision of dental care for medically compromised children in the UK by general dental practitioners. Int J of Paediatr Dent 2000;10(4):322-7.

\section{The Journal of} Haemophilia Practice

An open-access journal for sharing experience in the care of people with bleeding disorders

www.haemjournal.com 